\title{
A SUSTENTABILIDADE DA PRODUÇÃO DE MINERAIS INDUSTRIAIS EM REGIÕES METROPOLITANAS - UM ESTUDO DE CASO
}

\author{
M. S. Bezerra' \\ ${ }^{1} \mathrm{MB}$ Estudos e Projetos Ltda. \\ marcelosbezerra@globo.com
}

Artigo submetido em julho/2012 e aceito em agosto/2012

\section{RESUMO}

O trabalho aborda o panorama dos minerais industriais na região metropolitana do Recife, os principais depósitos, bem como as características físicas e químicas destes bens minerais são apresentadas, focando a sua aplicação industrial e a estrutura produtiva implantada que engloba micro, pequena e média empresa. Em seguida, é analisada a cadeia produtiva que transforma estes recursos em bens para a sociedade e os impactos ambientais e conflitos com outras atividades no uso e ocupação do solo, face ao intenso processo de expansão urbana e industrial na região. Surgem, assim, restrições de ordem ambiental, social e institucional que entravam o desenvolvimento do setor. Diante desse panorama são traçadas diretrizes comportamentais para o setor empresarial, enfatizando o papel governamental e a necessidade de ordenamento territorial para garantir a sustentabilidade da atividade.

PALAVRAS-CHAVE: minerais industriais, sustentabilidade, gestão territorial.

INDUSTRIAL MINERALS PRODUCTION SUSTAINABILITY IN LARGE METROPOLISES - CASE STUDY

\section{ABSTRACT}

This paper deals with industrial minerals in Recife metropolis, the principal deposits and physical and chemical characteristics of these minerals are presented focusing their industrial applications, by which a productive structure was then established involving micro, small and medium enterprises. After that, it is investigated the productive chain that transforms these resources in goods for the society, and competition against other activities in which soil occupation is concerned and nowadays this region is submitted to an accute process of urban and industrial expansion. In such case emerge environmental, social and institutional restrictions affecting the sector development and generating conflicts. In view this scenario are delineated comportamental directness to the entrepreneurs, emphasizing governmental actions and the need for territorial ordainment, looking for the mining activity sustainable.

KEY-WORDS: industrial minerals, sustainability, territorial management. 


\section{A SUSTENTABILIDADE DA PRODUÇÃO DE MINERAIS INDUSTRIAIS EM REGIÕES METROPOLITANAS - UM ESTUDO DE CASO}

\section{INTRODUÇÃO}

Sustentabilidade, conforme definida pelo relatório da Comissão Bundland (Eco 92 - Rio de Janeiro), é a abordagem do progresso que atenda às necessidades do presente, não comprometendo a capacidade de gerações futuras atenderem às suas próprias necessidades.

A Região Metropolitana do Recife constitui o principal polo populacional e econômico do Estado de Pernambuco, envolvendo 14 municípios que ocupam uma área total de 2.720 $\mathrm{km}^{2}$, com 3,7 milhões de habitantes que geram um PIB de R\$ 51 bilhões (2009). Essa região vem experimentando, nos últimos anos, um forte crescimento econômico que amplia a ocupação dos espaços territoriais e a demanda por bens e matérias primas diversas.

A dieta mineral é ativada pela demanda da construção civil, exigindo a abertura de novas minas ou a importação de produtos in natura ou industrializados de outras regiões do país. As restrições que se opõem ao desenvolvimento do setor mineral são, então, discutidas à luz dos conceitos da conservação e da sustentabilidade, focando a oferta, a demanda e as reservas minerais conhecidas.

\section{DEPÓSITOS E CARACTERIZAÇÃO MINERAL}

A região dispõe de minerais classificados como cerâmicos, físico funcionais, químicos e estruturais que são, a seguir, descritos em seus ambientes geológicos, que se formaram desde o proterozoico ao quaternário.

Tabela 1 - Recursos Minerais

\begin{tabular}{|c|l|l|}
\hline TEMPO GEOLOGICO & $\begin{array}{l}\text { UNIDADE } \\
\text { LITOESTRATIGRÁFICA }\end{array}$ & \multicolumn{1}{|c|}{ MINERAL } \\
\hline Quaternário & Coberturas Superficiais & Areia, argila \\
\hline Terciário & Grupo Barreiras & Argila, caulim \\
\hline \multirow{2}{*}{ Mesozoico } & Bacia sedimentar PE/PB & Calcário, argila, fosfato \\
\cline { 2 - 3 } & Bacia sedimentar Cabo & Argilito, caulim, calcário \\
\cline { 2 - 3 } & Suíte vulcânica Ipojuca & Tufo, riolito, traquito, basalto \\
\hline Proterozoico & Granitoides & $\begin{array}{l}\text { Pedra britada, rocha } \\
\text { ornamental }\end{array}$ \\
\hline
\end{tabular}

Algumas características físicas e químicas destes minerais são então apresentadas:

\section{Areia}

As areias são caracterizadas pela composição mineralógica, química e granulométrica para cada tipo de depósito (terraço marinho, aluvionar, cobertura arenosa e formacional sedimentar), conforme mostrado nas tabelas 2, 3 e 4. 
Verifica-se pela tabela 2 a predominância de areia quartzosa com até $99 \%$ de quartzo, sem presença de minerais deletérios, correspondendo os tipos mais impuros aos depósitos aluvionares.

Tabela 2 - Composição Mineralógica das Areias

\begin{tabular}{|c|c|c|c|}
\hline \multirow{2}{*}{ Tipo de Depósito } & \multicolumn{3}{|c|}{ Composição Mineralógica (\%) } \\
\cline { 2 - 4 } & quartzo & feldspato & acessórios \\
\hline Terraço marinho & 96 a 99 & 1 & $\begin{array}{c}\text { Imenita, rutilo, hematita, } \\
\text { magnetita, zircão, } \\
\text { turmalina, cianita, outros. }\end{array}$ \\
\hline Aluvionar & 83 a 96 & 3 a 15 & $\begin{array}{c}\text { Anfibólio, apatita, epidoto, } \\
\text { granada, ilmenita, hematita, } \\
\text { magnetita, outros. }\end{array}$ \\
\hline $\begin{array}{c}\text { Cobertura arenosa } \\
\text { Formacional } \\
\text { sedimentar }\end{array}$ & 99 & $<1$ & $\begin{array}{c}\text { Anfibólio, ilmenita, rutilo, } \\
\text { zircão, turmalina, } \\
\text { leucoxenio, estaurolita. }\end{array}$ \\
\hline
\end{tabular}

Fonte: CPRM

Pela composição química mostrada na tabela 3, predominam os teores de sílica, acima de 90 \% e de óxido de ferro, em torno de $1 \%$. Esses materiais são usados na construção civil e rodoviária, e os tipos mais puros, entram na composição de vidros e de produtos cerâmicos.

Tabela 3 - Composição Química das Areias

\begin{tabular}{|c|c|c|c|c|c|c|c|c|c|}
\hline \multirow{2}{*}{ Tipo de Depósito } & \multicolumn{7}{|c|}{ Composição Química (\%) } \\
\cline { 2 - 11 } & $\mathrm{SiO}_{2}$ & $\mathrm{Al}_{2} \mathrm{O}_{3}$ & $\mathrm{Fe}_{2} \mathrm{O}_{3}$ & $\mathrm{TiO}_{2}$ & $\mathrm{Na}_{2} \mathrm{O}$ & $\mathrm{K}_{2} \mathrm{O}$ & $\mathrm{CaO}$ & $\mathrm{MgO}$ & $\mathrm{PF}$ \\
\hline Terraço marinho & $>90$ & 0,14 & 0,84 & 0,3 & 0,05 & 0,05 & 0,01 & 0,01 & 0,16 \\
\hline Aluvionar & $>90$ & 4,1 & 1,33 & 0,25 & 0,38 & 1,97 & 0,15 & 0,07 & 0,72 \\
\hline Cobertura arenosa & $>90$ & 0,13 & 1,18 & 0,32 & 0,03 & 0,02 & 0,02 & 0,01 & 0,29 \\
\hline Formacional sedimentar & $>90$ & 0,56 & 1,15 & 0,12 & 0,01 & 0,03 & 0,01 & 0,01 & 0,15 \\
\hline
\end{tabular}

Fonte: CPRM

$\mathrm{Na}$ tabela 4, são mostradas as faixas granulométricas médias obtidas com amostras de areia, notando-se que os tipos mais grosseiros e com menor quantidade de argila e silte correspondem aos depósitos aluvionares e os mais finos, aos depósitos de terraços marinhos. 
Tabela 4 - Variação Granulométrica Média das Areias

\begin{tabular}{c|c|c|c}
\hline AREIA & $\begin{array}{c}\text { ALUVIONAR I } \\
\text { (\%) }\end{array}$ & $\begin{array}{c}\text { COBERTURA ARENOSA } \\
\text { (\%) }\end{array}$ & $\begin{array}{c}\text { TERRAÇO MARINHO } \\
\text { (\%) }\end{array}$ \\
\hline Fina & 27 & 48 & 67 \\
\hline Média & 58 & 39 & 28 \\
\hline Grossa & 11 & 2 & 1 \\
\hline Silte+Argila & 4 & 11 & 4 \\
\hline
\end{tabular}

Fonte: CPRM

Argila

Os principais depósitos de argila são classificados como sedimentos quaternários (aluvionar e planície de inundação), intempérico-residuais (alteração de rochas graníticas ou vulcânicas) e formacionais sedimentares.

Os sedimentos quaternários, de idade mais recente, constituem as argilas plásticas refratárias com as seguintes características: alta plasticidade; composição mineralógica, predominando a caulinita com a ilita e quartzo subordinados; absorção de água $\left(1200{ }^{\circ} \mathrm{C}\right)$ variando entre 17 e $20 \%$; resistência mecânica $\left(1200^{\circ} \mathrm{C}\right)$, variando entre 4,5 e $7 \mathrm{MPa}$. Quando o teor de ferro é inferior aos $4 \%$, a cor de queima se torna clara, e, quando excede, fica na faixa do laranja para o marrom. No primeiro caso a argila é usada na cerâmica branca (louça sanitária) e, no segundo caso, na fabricação do grés cerâmico.

Os depósitos intempérico-residuais são originados da alteração de rochas regionais, apresentando características diferenciadas, conforme o tipo da rocha original e da atuação do intemperismo.

Quanto aos depósitos de argila formacional, eles ocorrem em dois domínios geológicos, a saber: intercalação de argila em margas e calcários da formação Maria Farinha que são explorados, ativados e usados na fabricação de cimento pozolânico; camadas delgadas de argilito inseridas nos sedimentos da Formação Algodoais, ainda sem aproveitamento econômico. São materiais fundentes, mineralogicamente mais enriquecidos de ilita.

\section{Caulim}

O caulim ocorre na região, e os depósitos mais importantes foram formados pela ação do intemperismo atuante sobre rochas vulcânicas da Formação Algodoais. Nesse caso, a composição mineralógica apresenta, essencialmente, caulinita e quartzo. Estudos realizados por Araújo, A. de P. R. et al. mostram resultados de rendimento na peneira ABNT 325, entre 40 e $50 \%$ e alvura superior a $80 \%$, com possibilidade de uso na indústria de papel, tinta e cerâmica, fato que corrobora a sua ampla comercialização.

Existem, também, depósitos de menor importância originados do intemperismo sobre rochas granitoides com mineralogia constituída de caulinita (49\%) e quartzo (50\%), que podem demandar a necessidade de beneficiamento prévio para algumas aplicações. Relatamse também depósitos de caulim sedimentar no Grupo Barreiras, ainda sem aproveitamento. 


\section{Tufo vulcânico}

É uma rocha vulcânica com matriz fina, contendo fragmentos de diversos tipos de rocha que é considerada como uma pozolana natural, sendo por isto utilizada como aditivo na fabricação de cimentos especiais.

\section{Pedra britada}

As pedreiras de pedra britada estão concentradas em áreas onde, petrograficamente, predominam as rochas magmáticas plutônicas, explorando os granitoides regionais.

\section{Outros bens minerais}

As minas de fosfato e de calcário localizadas ao norte da região foram fechadas nas décadas de 1960 e 1980, por interferência do crescimento urbano e das zonas de preservação, prenunciando as dificuldades para o setor mineral regional.

Registra-se a ocorrência de rochas ornamentais em fase de produção experimental e outras, como, diábase e com teores de potássio e outros elementos acima de $10 \%$, ainda sem aproveitamento, mas com potencial para geração de novas jazidas, visando à oferta de materiais fundentes cerâmicos e de agrominerais portadores de nutrientes para a agricultura local.

\section{NÍVEIS DA PRODUÇÃO MINERAL}

A produção mineral, na região, é estimada em torno de nove milhões de toneladas (2008), sendo a areia e a pedra britada os principais participantes. A areia e a pedra britada são produtos ofertados, e a tabela 5 mostra a evolução da produção nos últimos anos, excluídos os dados do caulim que estão embutidos nas argilas.

Tabela 5 - Evolução da Produção Mineral na RMR (t).

\begin{tabular}{l|c|r|c|c|c}
\hline ANO & AREIA & $\begin{array}{r}\text { PEDRA } \\
\text { BRITADA }\end{array}$ & $\begin{array}{c}\text { ARGILA } \\
\text { PLÁSTICA }\end{array}$ & $\begin{array}{c}\text { ARGILA } \\
\text { REFRATÁRI } \\
\text { A }\end{array}$ & $\begin{array}{c}\text { TUFO } \\
\text { VULCANICO }\end{array}$ \\
\hline $\mathbf{2 0 0 4}$ & 3.455 .114 & $\begin{array}{r}2.245 .95 \\
8\end{array}$ & 141.163 & 17.946 & 52.464 \\
\hline $\mathbf{2 0 0 5}$ & 3.243 .249 & $\begin{array}{r}2.029 .40 \\
7\end{array}$ & 167.581 & 181.394 & 79.088 \\
\hline $\mathbf{2 0 0 6}$ & 4.450 .994 & $\begin{array}{r}2.408 .08 \\
3\end{array}$ & 130.185 & 99.785 & 83.079 \\
\hline $\mathbf{2 0 0 7}$ & 5.041 .520 & $\begin{array}{r}2.618 .34 \\
7\end{array}$ & 216.914 & 111.056 & 88.184 \\
\hline $\mathbf{2 0 0 8}$ & 5.842 .206 & $\begin{array}{r}2.902 .40 \\
6\end{array}$ & 279.126 & 121.188 & 98.660 \\
\hline $\mathbf{2 0 0 9}$ & 6.200 .000 & $\begin{array}{r}6.000 .00 \\
0\end{array}$ & 37.635 & 198.200 & 135.300 \\
\hline
\end{tabular}


Fonte: CPRM adaptado do DNPM

\section{ESTRUTURA PRODUTIVA}

A estrutura produtiva dos minerais para construção civil envolve empresas de pequeno, médio e grande porte ao lado de muitas pequenas empresas familiares e informais, operando de modo intermitente. As principais minas em operação, na RMR, são apontadas na tabela 6, classificadas pelo porte, definido com base na produção anual (volume físico).

Tabela 6 - Porte das Principais Minas

\begin{tabular}{l|c|c|c|c|c|c|c}
\hline \multirow{2}{*}{ SUBSTÂNCIA } & \multicolumn{7}{|c}{ PORTE DAS MINAS } \\
\cline { 2 - 8 } & P1 & P2 & P3 & P4 & M4 & G1 & TOTAL \\
\hline Areia & 1 & 4 & - & 1 & - & 2 & 8 \\
\hline Argilas & 1 & 2 & 2 & - & - & - & 5 \\
\hline Tufo vulcânico & 1 & - & - & - & - & - & 1 \\
\hline Pedra britada & - & 1 & 3 & - & 1 & 1 & 6 \\
\hline Total & 3 & 7 & 5 & 1 & 1 & 3 & 20 \\
\hline
\end{tabular}

$\mathrm{P} 1=10 \mathrm{mil} t / \mathrm{ano}$ a $20 \mathrm{mil} \mathrm{t} / \mathrm{ano} ; \mathrm{P} 2=20 \mathrm{mil} \mathrm{t} / \mathrm{ano} ; \mathrm{P} 3=50 \mathrm{mil} \mathrm{t} / \mathrm{ano}$ a $100 \mathrm{mil} \mathrm{t} / \mathrm{ano} ; \mathrm{P} 4=$ 100 mil t/ano a 500 mil t/ano; M4= 500 mil t/ano a um milhão t/ano; e G1= um milhão de t/ano a três milhões de t/ano.

Fonte: atualizado de Universo da Mineração Brasileira (DNPM, 2007).

\section{RESTRIÇÕES À PRODUÇÃO}

A forma desordenada de crescimento urbano e a falta de planejamento do uso do solo dificultam um ordenamento do espaço disponível e a compatibilização entre a atividade mineral e outros usos. Foram identificadas as seguintes restrições na região:

Zonas de preservação ambiental nos seguintes tipos de ecossistemas: zonas de uso urbano, turismo e veraneio; zona urbana industrial e portuária; zonas de estuário e ecossistemas integrados; zonas de preservação florestal e proteção dos mananciais; zonas de proteção do aquífero Beberibe; zonas de preservação e conservação da vida silvestre.

Planos Municipais: não consideram estes instrumentos de política pública: a peculiaridade da rigidez locacional das jazidas minerais e a sua importância como um fator de adensamento de cadeias produtivas.

Licenças e Outorgas: tramitação burocrática dos processos de outorga de direitos minerais e de licenciamento ambiental pelas esferas municipal, estadual e federal, com pouca integração entre os órgãos responsáveis.

Propriedade da terra: anuência do proprietário e falta de entendimento do preceito constitucional sobre a distinção entre propriedade do solo e do subsolo.

Informalidade: atividade de mineração realizada clandestinamente depreda as jazidas e 
acumula um passivo ambiental que onera a imagem do setor mineral.

Expansão urbana e industrial ocupando áreas de interesse para a mineração, por falta de ordenamento territorial.

\section{O SETOR DEMANDANTE}

As substâncias minerais produzidas, na região, são utilizadas in natura, ou sob a forma de produtos decorrentes da transformação industrial, na cadeia da construção civil (Figura 1).

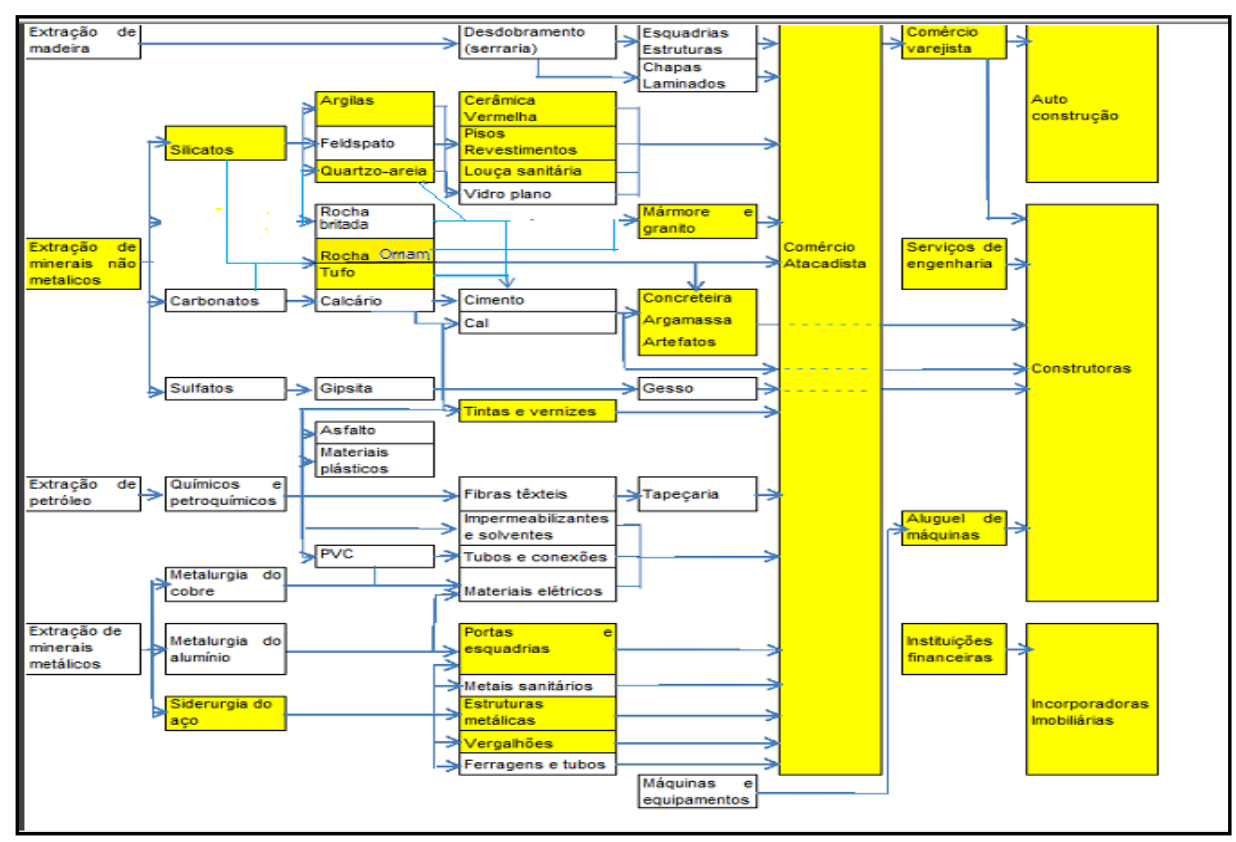

FIGURA 1 - A Cadeia produtiva da Construção Civil

Nesta cadeia, são destacados, na cor amarela, os elos produtivos presentes, na região, restringindo-se a atividade de extração a alguns minerais não metálicos do grupo dos silicatos e, na transformação industrial, os produtos cerâmicos e siderúrgicos. Ressalta, ainda, a forte dependência dos elos à jusante da cadeia (comércio e construtoras), a materiais que são fornecidos totalmente por outros centros produtores. Reforçando a assertiva, os principais produtos minerais consumidos, na região, já veem sendo buscados fora da região: $30 \%$ da areia, $20 \%$ da pedra britada e $70 \%$ da argila para fins cerâmicos.

Um sintoma desse panorama é o fato inovador constatado de já se fazer aproveitamento de areia rejeitada, como pó de brita ou beneficiada, a partir de arenitos argilosos do grupo Barreiras. Também se desenvolvem experimentos para substituição da pedra britada por resíduos de construção moídos.

No que tange à demanda futura, observa-se, ainda, na região, um período de intenso crescimento econômico que trará impacto positivo na construção civil e na demanda de minerais industriais. São projetos de investimentos privados, estruturadores (refinaria, polo petroquímico, polo naval, siderúrgica, montadoras de automóveis e motocicletas, termoelétricas e fábricas de equipamentos eólicos etc.); investimentos governamentais em 
infraestrutura (sistema de esgoto sanitário, arena e estádio da copa, adutora, rodovias, metrô, equipamentos urbanos e dragagem do porto de Suape); crescimento residencial (Índice de Velocidade de Vendas do mercado imobiliário regional superando a marca de 60 mil unidades anuais, nos últimos cinco anos), projetando-se, para a década 2010/2020 (SINDUSCON/PE), um crescimento da construção civil na média de $8 \%$ ao ano.

Essas projeções foram utilizadas, como base para previsão do consumo de areia e brita, no ano 2020, diante de três cenários de demanda que são caracterizados na tabela 7.

Tabela 7 - Projeção da Demanda de Areia e Pedra Britada (2020)

\begin{tabular}{c|l|l|c}
\hline \hline CENÁRIO & DENOMINAÇÃO & \multicolumn{1}{|c|}{ CARACTERIZAÇÃO } & $\begin{array}{c}\text { DEMANDA EM } \\
\mathbf{2 0 2 0}(\mathbf{m i l} \text { t) }\end{array}$ \\
\hline 1 & Conservador & $\begin{array}{l}\text { Manutenção da taxa de } \\
\text { consumo histórica. }\end{array}$ & $\begin{array}{c}\text { Areia: } 9.600 \\
\text { Pedra Britada: } 4.100\end{array}$ \\
\hline 2 & Moderado & $\begin{array}{l}\text { Estabilidade econômica e } \\
\text { crescimento a taxa média de 4 } \\
\%\end{array}$ & $\begin{array}{c}\text { Areia: 8.700 } \\
\text { Pedra Britada: } 4.500 \\
\mathrm{t}\end{array}$ \\
\hline 3 & $\begin{array}{l}\text { Desenvolvimentist } \\
\text { a }\end{array}$ & $\begin{array}{l}\text { Crescimento da construção a } \\
\text { taxa média anual de 8\%. }\end{array}$ & $\begin{array}{c}\text { Areia: 13.700 } \\
\text { Pedra Britada: 7.100 }\end{array}$ \\
\hline
\end{tabular}

\section{RESERVAS MINERAIS}

As reservas minerais, oficialmente levantadas pelo Anuário Mineral Brasileiro do DNPM, são disponibilizadas por unidade da federação, de forma que, apresentamos, neste trabalho, uma estimativa de recursos, inferida pela CPRM, que, comparada aos níveis de produção de 2009 (tabela 5), de cada bem mineral, nos permite admitir como praticamente inesgotáveis os depósitos, com exceção dos da areia que poderão estar exauridos em três décadas.

\section{DIRETRIZES PARA A SUSTENTABILIDADE}

A mineração, na RMR, se desenvolve em espaço territorial de forte pressão demográfica, de crescente dinamismo industrial e urbano, por um lado e, por outro, submetido a zoneamentos ambientais restritivos. São fatos irreversíveis. A limitação dos espaços conduz, naturalmente, ao agravamento de conflitos da mineração com diferentes interesses no uso e ocupação do solo. É uma disputa de negócios.

Se o mercado demanda cada vez mais a oferta de matérias primas, por outro lado se intensificam as pressões da sociedade para uma melhor qualidade de vida das pessoas, sendo feitas restrições às atividades que não se enquadram nos conceitos de desenvolvimento sustentável. 
A sustentabilidade da atividade passa, necessariamente, pela interação entre instituições do governo, comunidades envolvidas e empreendedores; estes, preferencialmente, representados por entidades de classe.

Dentro destes preceitos, são elencadas, a seguir, algumas ações que se fazem necessárias para dar uma melhor sustentabilidade à produção mineral na RMR:

\section{Ao Minerador:}

Adotar práticas de mineração tecnicamente estruturadas e adequadas com a fragilidade de cada ambiente a ser minerado.

Desenvolver ações junto com o Sindicato das Indústrias de Construção Civil (SINDUSCON/PE) para certificar fornecedores devidamente legalizados junto às construtoras e lojas de materiais de construção, para evitar o uso de materiais explorados de modo inadequado ou de baixa qualidade para construção de moradias e de obras de interesse coletivo.

Desenvolver campanhas dirigidas ao público consumidor e às comunidades próximas das áreas de mineração, demonstrando os cuidados ambientais e as normas de segurança implantadas, bem como ressaltar os benefícios da atividade mineral.

Conscientizar os empregados sobre a adoção de procedimentos adequados à manutenção da atividade mineral em consonância com a questão ambiental, a saúde e a segurança no trabalho e as normas reguladoras da legislação trabalhista.

Demonstrar para a sociedade a diminuta área territorial requerida por unidade do produto mineral lavrado e o seu expressivo retorno financeiro por unidade de área ocupada. Restaurar a área minerada concomitante ao avanço da lavra, disponibilizando-a mais cedo para novos usos.

\section{Aos Órgãos de Governo:}

Otimizar a gestão do patrimônio mineral, exigindo dos mineradores a realização de trabalhos de dimensionamento e aproveitamento adequado de reservas, especialmente areia, pedra britada e argila.

Com referência às argilas, as reservas minerais, na Bacia do Cabo, merecem uma atenção especial, em decorrência das características tecnológicas específicas de alguns destes materiais que podem ser colocados na categoria de jazidas de classe nacional. Assim, para melhor gestão desse patrimônio mineral, torna-se necessária a reavaliação das reservas localizadas em áreas sem restrições ambientais e a quantificação, conforme a qualificação da argila.

Contemplar o setor mineral em planos diretores e em planos de ordenamento territorial dos municípios, como forma de garantir o suprimento de materiais imprescindíveis à sociedade. Atuação conjunta com representação dos mineradores.

Inibir a atividade produtiva informal e clandestina, evitando a exploração predatória de jazidas e danos ambientais causados por esta prática que traduz uma imagem negativa do setor mineral. Ações, nesse sentido, podem ser conjugadas com estímulo a práticas de 
cooperativismo e associativismo, minimizando impactos sociais e aplicação do modelo de Ajustamento de Conduta para adequação da pequena mineração a melhores níveis produtivos.

\section{CONCLUSÕES}

O arcabouço geológico regional salienta a ocorrência e a produção na região de diversos minerais industriais, destacando-se, pelos volumes de produção, a areia e a brita, cujas projeções de consumo, para o ano 2020, apontam para uma duplicação das necessidades atuais, dentro de um cenário de crescimento econômico com fundadas expectativas de manutenção deste ritmo, durante a próxima década, o que ampliará a demanda por insumos minerais para construção. Estas jazidas assumem um papel de relevante interesse para o desenvolvimento da mineração e para o suprimento aos segmentos das indústrias de construção civil, de cerâmicas de louça sanitária e de revestimentos, e do cimento. Outro aspecto importante a ser destacado é a interação, muitas vezes inadequada, da atividade mineral com a expansão urbana e outras formas de uso do meio físico, o que tende a impedir a exploração de reservas existentes, e as áreas de produção mineral cada vez se afastam para fora dos limites da região, encarecendo os custos dos insumos industriais.

Diante desse cenário, faz-se urgente a sinergia entre produtores, representantes de consumidores e gestores públicos das diferentes esferas governamentais, no sentido de inovações no processo produtivo e na comercialização, adequando a mineração às diretrizes de planos diretores municipais e de ordenamento territorial.

O desafio, que se coloca para a sociedade, é assegurar o suprimento dos insumos minerais para a construção civil com a manutenção da qualidade ambiental, provendo a ocupação territorial com a obtenção dos maiores benefícios sociais e econômicos para a população.

A solução do impasse deve considerar o benefício econômico da mineração e a sua característica de atividade transitória, a peculiaridade da rigidez locacional das jazidas e as práticas de mineração adequadas ao equilíbrio ambiental.

\section{REFERÊNCIAS BIBLIOGRÁFICAS}

1. ARAÚJO, A. de P. R.; BARAÚNA, O. S. Estudo Tecnológico dos Caulins Sedimentares da Faixa Costeira ao Sul de Recife, Estado de Pernambuco. In: Revista Pernambucana de Tecnologia, v.1, $n^{\circ} 1$, set./dez., Recife, 1981, pp.67-100.

2. CPRM - SERVIÇO GEOLÓGICO DO BRASIL. Projeto Insumos Minerais para a Construção Civil na Região Metropolitana do Recife. Recife: CPRM, 2011. Programa Geologia do Brasil. Série Rochas e Minerais Industriais, $\mathrm{n}$ o 8.

3. CPRM - SERVIÇO GEOLÓGICO DO BRASIL. MELLO, Ivan Sergio de Cavalcanti. Atlas de matérias primas cerâmicas do nordeste brasileiro / Ivan Sergio de Cavalcanti Mello, José Francisco Marciano Motta, Marcelo Soares Bezerra, Julio de Rezende Nesi, Roberto Loretti Junior. São Paulo : CPRM, 2011. 184 p., Il.

4. DNPM - Departamento Nacional da Produção Mineral. Anuário Mineral Brasileiro 2010. Disponível em www.dnpm.gov.br. Acesso em: 20 set 2012. 